\title{
TESTE COM BARRA EM AFLORAMENTO COM OCORRÊNCIA DE CARVÃO NO MUNICÍPIO DE CANDIOTA - RIO GRANDE DO SUL: USO DO MÉTODO GPR PARA MEDIDAS DE PERMISSIVIDADE ELÉTRICA
}

\author{
Jesus, F. A. N., LASG-UNIPAMPA; Caron, F., LASG-UNIPAMPA
}

Copyright 2018, SBGf - Sociedade Brasileira de Geofísica

Este texto foi preparado para a apresentação no VIII Simpósio Brasileiro de Geofísica, Salinópolis, 18 a 20 de setembro de 2018. Seu conteúdo foi revisado pelo Comitê Técnico do VIII SimBGf, mas não necessariamente representa a opinião da SBGf ou de seus associados. É proibida a reprodução total ou parcial deste material para propósitos comerciais sem prévia autorização da SBGf.

\section{Resumo}

This study was carried out with the purpose of obtaining electrical physical properties of rocks associated to the occurrence of coal in Candiota, Rio Grande do Sul, aiming to add potential for the use of the GPR method to support the exploration of coal in the region. The measurements were made through a speed test with metal bars inserted in a rocky cut the edges of the BR293. As a result, relative electrical permittivity values of 6.04957 and 42.79289 were obtained for sandstones and siltstones, respectively. From the results obtained it is expected to provide calibration parameters for future GPR campaigns in Candiota and similar lithologic context sites.

\section{Introdução}

Nos últimos 40 anos, a Geofísica vem atuando na exploração de carvão mineral devido a significativa distinção dos parâmetros petrofísicos deste minério em relação as rochas associadas à sua ocorrência (HATHERLY, 2013; THOMAS, 2013). As duas principais escalas de pesquisa são: pequena (mapeamento geológico, delimitação do enquadramento sedimentar e regime estrutural da área, etc.) e grande (delimitação de áreas com maior viés econômico, identificação de descontinuidades, detecção de espaços vazios, etc.) onde são utilizados principalmente os métodos eletromagnéticos, elétricos e sísmicos. Em projetos de grande escala, Kai (2012) menciona a ineficiência de determinados métodos geofísicos na localização de alvos superficiais (inferiores a $100 \mathrm{~m}$ de profundidade). $\mathrm{O}$ autor cita o caso da sísmica rasa devido a interferência de ondas diretas, refratadas e superficiais. O autor destaca o método Ground Penetrating Radar (GPR) na exploração de alvos localizados em profundidades inferiores a $50 \mathrm{~m}$, contemplando requisitos de precisão e anti-interferência. Molinda (1996), Save (2004) e Strange (2005), em três estudos realizados em minas ativas de carvão, apontam que para a extração de melhores resultados do método GPR existe a necessidade do controle dos parâmetros petrofísicos das litologias exploradas e associadas, ressaltando sobre a grande variabilidade destes parâmetros em pacotes sedimentares.

Os depósitos de carvão de importância econômica no Brasil ocorrem na porção Sul do país. Segundo Kalkreuth (2006), Seccatore, Marin e Tomi (2011) as reservas brasileiras, são de 32 bilhões de toneladas, das quais $89,23 \%$ estão localizadas no Rio Grande do Sul. A Jazida Candiota, localizada no munícipio de Candiota é a maior do país, representando a parcela de $40 \%$ do total dos recursos nacionais e $44 \%$ dos recursos do Estado do Rio Grande do Sul (RAMGRAB \& WILDENER, 1999). As camadas de carvão inseridas no topo da Formação Rio Bonito, descrita detalhadamente no trabalho de Holz (2006), possuem caráter uniforme, ampla distribuição espacial e relativamente pequena espessura. A posição das camadas e das coberturas segundo o relatório geológico da Folha Pedro Osório (RAMGRAB; WILDNER, 1999), são influenciadas por falhas que propiciam a ocorrência de extensas áreas com coberturas inferiores a $50 \mathrm{~m}$, o que Ihes agrega potencial exploratório.

O objetivo deste estudo é possibilitar através da estimativa de velocidade de ondas eletromagnéticas, a discrição petrofísica de rochas associadas a ocorrência de carvão da Formação Rio Bonito no município de Candiota, de forma que essas informações possam contribuir para futuras campanhas de GPR em apoio a exploração de carvão na região. Para isso foi locado um perfil na margem da rodovia BR-293, no quilômetro 137, próximo a cidade de Candiota (Figura 1), onde foi verificado e nomeado 0 afloramento PST nas coordenadas $31,46462 \mathrm{~S} / 53,66579$ O $(6515827,50$ S/246708,04 E, 22J) para aplicação do método de teste com barra para estimativa de velocidade.

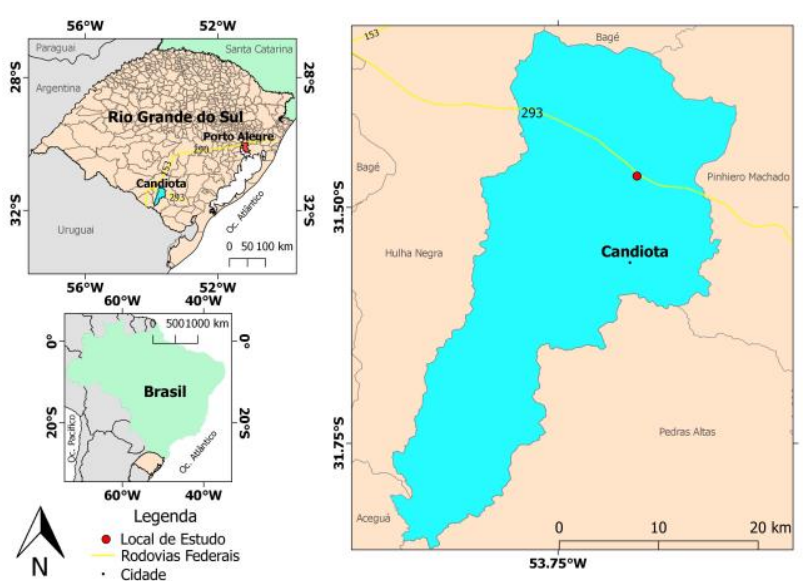

Figure 1 - Mapa de localização da área de estudo (datum: SIRGAS2000), feito a partir de shapefiles disponíveis no geobank, CPRM (2017).

Na Figura 2 é indicada a posição do afloramento e do perfil em relação a ocorrência geológica do local. $\mathrm{Na}$ Figura 3 é apresentada uma imagem do afloramento e do 
perfil (nomeado Perfil PST) ressaltando o conjunto de litologias aflorantes.
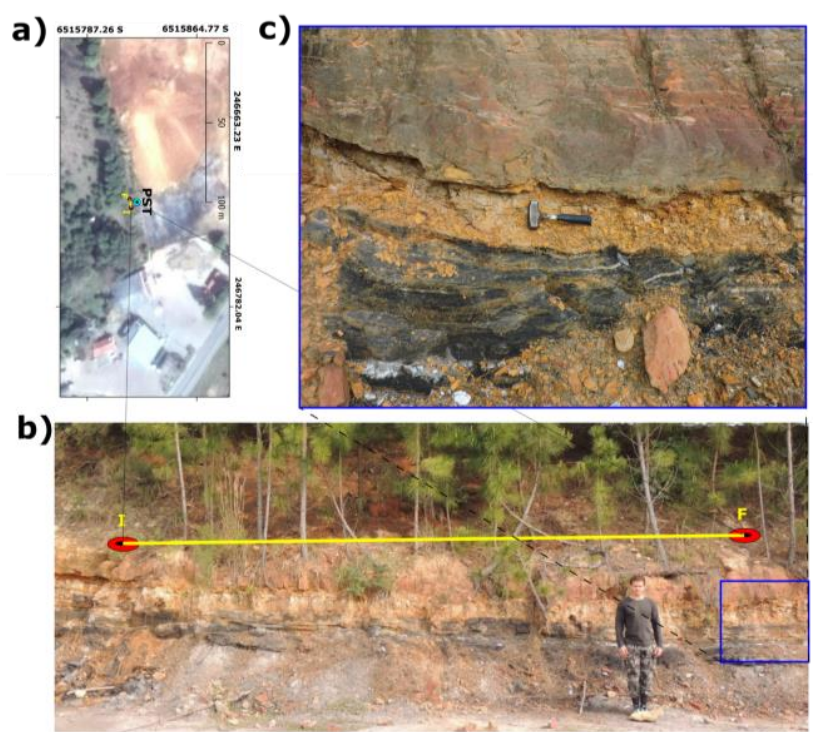

Figure 3- a) Imagem de satélite destacando o b) Perfil $P S T$ e as c) litologias visíveis no afloramento PST.

\section{Materiais e Métodos}

Daniels (2004) e Jol (2009) descrevem três métodos para estimativa de velocidade da onda eletromagnética: medidas laboratoriais de condutividade e constante dielétrica, posicionamento de um objeto anômalo para medida do Two-Way-Traveltime (TWT) e análise de velocidade em ponto comum. O segundo método foi apresentado por Conyers e Lucius (1996) através de um teste realizado com duas barras de ferro posicionadas em diferentes locais de um perfil durante uma campanha arqueológica. A Figura 4 ilustra a interação de um objeto anômalo enterrado e o sinal eletromagnético do GPR. A Figura 5 ilustra a característica hiperbólica resultante dessa iteração.

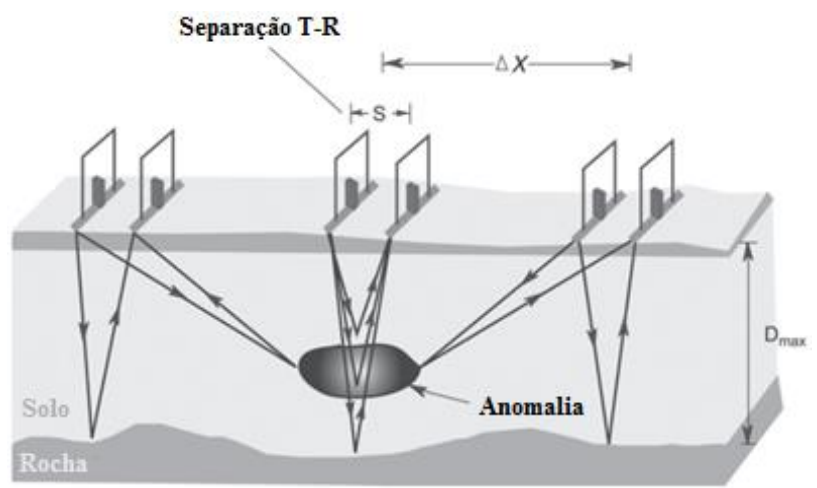

Figure 4 - Interação de um objeto enterrado (anômalo) com o sinal eletromagnético do GPR, $T$ é referente a antena transmissora e $R$ a receptora, imagem adaptada de Annan (2005).

A velocidade obtida pelo TWT (velocidade aparente Vrms, Equação 1) é o valor referente ao pacote total até a interface causadora da reflexão $\left(\Delta X_{n}\right)$, representa 0 tempo que a onda chega ao refletor e retorna ao receptor. A partir da Equação de Dix (Equação 2), a velocidade aparente é convertida na velocidade das camadas (n) que compõe esse pacote (velocidade intervalar, vint), que ao ser descrita em termos das propriedades físicas do meio rochoso (permissividade elétrica $\varepsilon$ e permeabilidade magnética $\mu$ ) que a onda atravessa assume uma forma simplificada (Equação 3).

a)

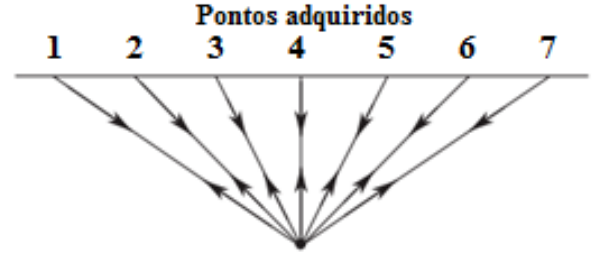

b)

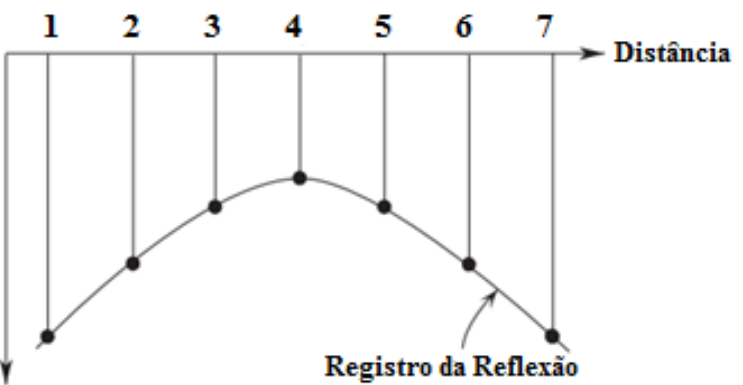

TWT

Figure 5 - a) pontos adquiridos na aquisição e b) 0 registro no tempo dos pontos adquiridos (traços), ilustração adaptada de Neal (2004).

$$
\begin{gathered}
v_{r m s}=\frac{2 \Delta x_{n}}{t_{n}} \\
v_{\text {int } n}=\sqrt{\left[\frac{\left.\left(v_{r m s_{n} n}\right)^{2} t_{n}-\left(v_{r m s_{n}-1}\right)^{2} t_{n-1}\right]}{t_{n}-t_{n-1}}\right]} \\
v_{\text {int } n}=\frac{1}{\sqrt{\varepsilon \mu}}
\end{gathered}
$$

Os dados de GPR foram adquiridos em duas seções (com e sem alvos) com mesmos parâmetros de janela de aquisição (100 ns), número de amostras no tempo (384) e taxa de amostragem espacial $(0,0278 \mathrm{~m})$. A antena utilizada foi de $200 \mathrm{MHz}$, desenvolvida pela (c) Ingegneria Dei Sistemi (IDS), com arranjo Common Offset (afastamento comum de fonte e receptor), orientação de antenas paralelas entre si e paralelas a orientação das barras. Como alvos foram utilizadas duas vigas de aço (0,02 $\mathrm{m}$ de diâmetro e 1,30 $\mathrm{m}$ de comprimento), posicionadas em relação a mudança de fácies do afloramento. O primeiro alvo foi posicionado a $1,81 \mathrm{~m}$ do início do perfil a $0,75 \mathrm{~m}$ de profundidade, o segundo foi posicionado a 2,61 $\mathrm{m}$ do início do perfil a $1,10 \mathrm{~m}$ de profundidade. As etapas de processamento adotadas são apresentadas no fluxograma (Figura 6) e realizadas no software ReflexW, desenvolvido pela (CSandmeier Geophysical Research. Os mesmos parâmetros de processamento foram utilizados em ambas seções. 


\section{Dados brutos \\ Dewow \\ Correção Estática \\ Função Ganho \\ Corte no Tempo \\ Passa-banda \\ Ganho Manual \\ Reversão \\ Background Removal \\ Correção Topográfica \\ Dados processados}

Figure 6 - Fluxograma das etapas de processamento aplicadas aos dados.

O conceito adotado para a descrição facilógica foi retirado do livro Facies Model 4 (JAMES \& DALRYMPLE, 2010). Para interpretação das fácies descritas, foi utilizada a tabela de descrição litofacilógica de assinaturas estratigráficas da Bacia do Paraná, publicada no trabalho de Holz (2006).

\section{Resultados}

A partir da correlação de Fácies descritas por Holz (2006), são apresentados os resultados de descrição das fácies do afloramento PST (Figura 7), onde puderam ser atribuídas interpretações dos ambientes de formação de cada fácies.

\begin{tabular}{|c|c|c|c|}
\hline Fácies & Nome & Descrição & Interpretação \\
\hline & C & $\begin{array}{l}\text { Arenito médio a grosso, } \\
\text { coloração avermelhada, } \\
\text { estratificação subparelela, } \\
\text { grãos com alto grau } \\
\text { de oxidação }\end{array}$ & $\begin{array}{l}\text { Ambiente com } \\
\text { alternância de } \\
\text { energia de fluxo sob } \\
\text { influênciade ondas }\end{array}$ \\
\hline & B & $\begin{array}{c}\text { Siltito, } \\
\text { coloração amarelada, } \\
\text { acamamento lenticular, } \\
\text { alto grau de intemperismo }\end{array}$ & $\begin{array}{l}\text { Ambiente de baixa } \\
\text { energia com deposição } \\
\text { de sedimentos } \\
\text { em suspensão }\end{array}$ \\
\hline & A & $\begin{array}{l}\text { Carvão, coloração } \\
\text { de cinza escuro a preta, } \\
\text { lentes de carbonatos, } \\
\text { acamamento lenticular }\end{array}$ & $\begin{array}{c}\text { Acumulação } \\
\text { agradacional de } \\
\text { matéria orgânica e } \\
\text { grãos detríticos finos }\end{array}$ \\
\hline
\end{tabular}

Figure 7 - Relação de Fácies descritas no afloramento PST e a interpretação do ambiente de formação, segundo Holz (2006).

A aquisição de dados feitas a partir dos parâmetros definidos no item anterior resultou nos radargramas apresentados na Figura 8. Ao observar a Figura 8 é possível verificar boa penetração do sinal até o tempo de 30 ns. Neste mesmo tempo pode-se identificar a presença de um refletor bem definido com continuidade do início ao final do perfil. Em tempos superiores a 30 ns é possível notar atenuação abrupta do sinal eletromagnético, possivelmente associada a presença deste refletor continuo. a)

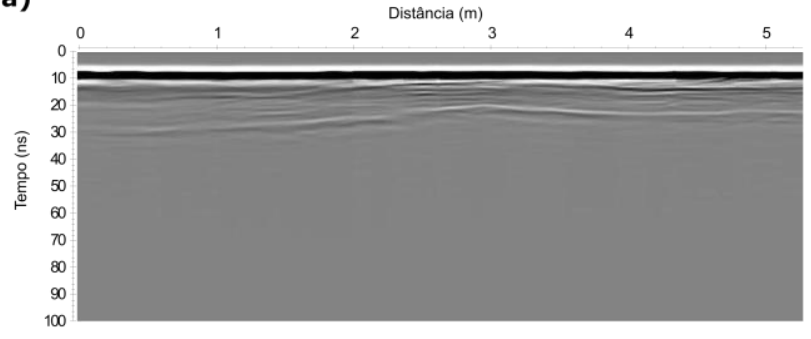

b)

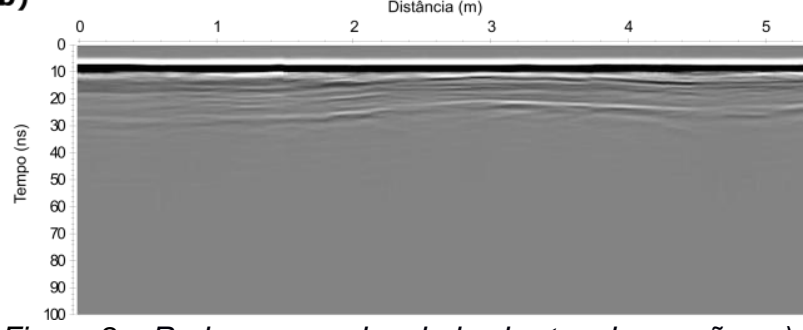

Figure 8 - Radargramas dos dados brutos das seções a) sem alvos e b) com alvos.

Após a aplicação do fluxograma de processamento apresentado no item anterior foram gerados os radagramas da Figura 9. Ao observar os radagramas na Figura 9 é possível notar o mesmo refletor continuo no tempo de $11 \mathrm{~ns}$ (evidenciado por setas vermelhas). Ainda na mesma imagem é possível identificar a presença de um segundo refletor (evidenciado por setas amarelas), bem definido por toda a seção (Figura 10a) e entre as distâncias horizontais de 0 a $1,5 \mathrm{~m}$ e 3 a $4,5 \mathrm{~m}$ (Figura 10b), localizado a partir do tempo de $33 \mathrm{~ns}$.

a)

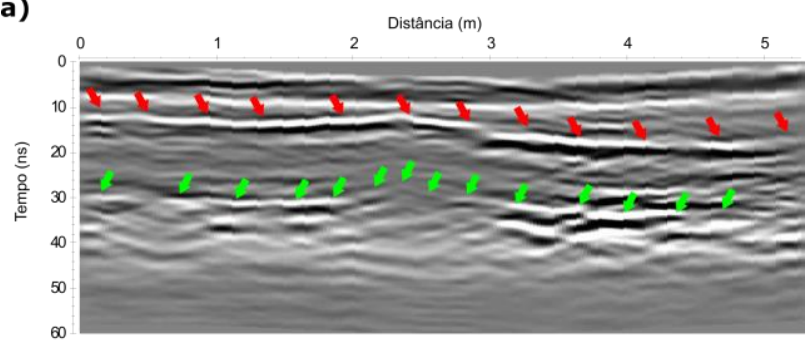

b)

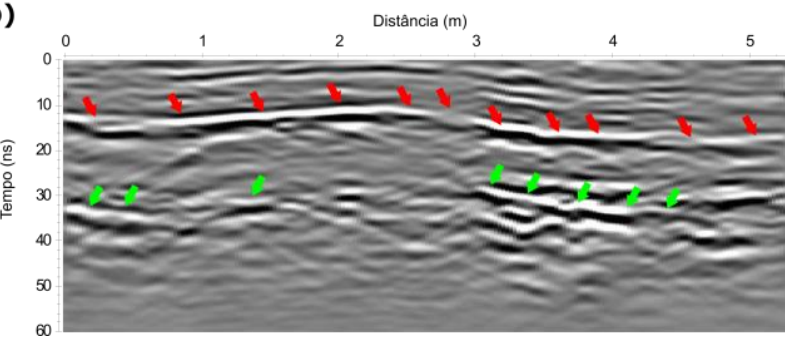

Figure 9 - Seções a) sem alvos e b) com alvos após aplicação do fluxograma de processamento, as flechas vermelhas indicam a posição do primeiro refletor e as verdes indicam a posição do segundo refletor.

A identificação dos alvos foi feita através da comparação entre as seções com e sem alvo (Figura 10). Através da comparação é possível verificar a presença de feições hiperbólicas (associadas a presença dos alvos) posicionadas juntamente aos dois refletores previamente identificados. 
a)

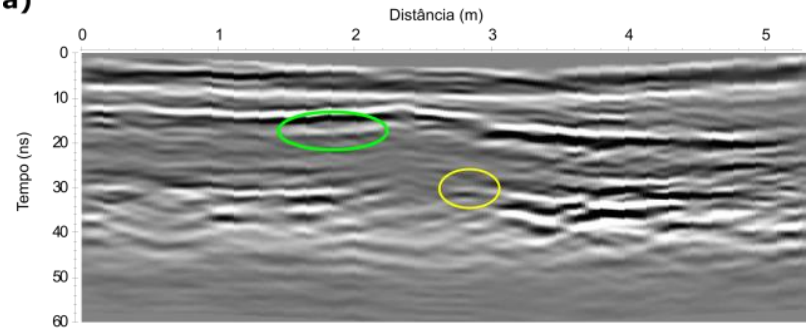

b)

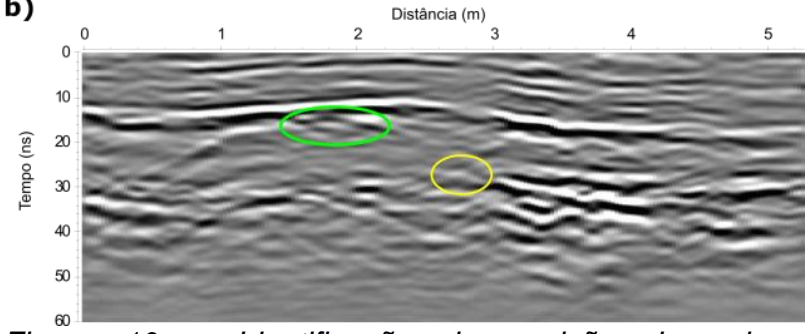

Figure 10 - Identificação da posição dos alvos, destacados nas elipses verdes e amarelas, a partir da comparação entre os refletores das seções a) sem alvo) e b) com alvo.

O Alvo 1, evidenciado pela elipse verde, produz uma feição hiperbólica no radargrama em conjunto com diminuição de alcance do sinal emitido, verificada pela dificuldade no rastreamento do segundo refletor na região inferior ao alvo (Figura 10b). O Alvo 2, evidenciado pela elipse amarela, produz uma feição hiperbólica com abertura reduzida, indicativo de uma velocidade de propagação menor.

A posição obtida, em função da distância horizontal $(\mathrm{m})$ e do TWT (ns), foi posteriormente relacionada com as medidas de controle dos alvos em campo, em profundidade $(\mathrm{m})$ e distância horizontal $(\mathrm{m})$. Através da posição $(x, t)$ dos alvos foram realizados cálculos para estimativa dos valores de velocidade dos pacotes 1 e 2 e associações dos refletores com as superfícies de contato entre as Fácies $A, B$ e $C$. Onde foram encontrados os valores de $0,13636 \mathrm{~m} / \mathrm{ns}$ para o pacote 1 e $0,06667 \mathrm{~m} / \mathrm{ns}$ para o pacote 2 .

A partir das velocidades de cada pacote em conjunto com a equação de Dix foram calculados os valores de velocidades intervalares referentes as Fácies $C$ e $B$ respectivamente. No primeiro intervalo (Fácies $C$ ) foi mantido o valor do pacote 1 de $0,13636 \mathrm{~m} / \mathrm{ns}$ e para o segundo intervalo (Fácies B) foi calculado o valor de $0,05127 \mathrm{~m} / \mathrm{ns}$. Através dos valores de velocidade intervalares obtidos em conjunto com a equação $x$ foram calculadas as permissividades elétricas de cada intervalo (de cada Fácies), adotando a permeabilidade magnética como 1. Como resultados foram obtidos os valores de $53,78065 \mathrm{pF}$ para o primeiro intervalo (Fácies C) e 380,42878 pF para o segundo intervalo (Fácies B). A partir dos valores de permissividades elétricas foram obtidos os valores relativos destas através da conversão realizada por meio da relação $\varepsilon_{\text {relativa }}=\varepsilon / \varepsilon_{0}$ (permissividade elétrica do vácuo $\varepsilon_{0}$ ). Os resultados foram 6,04957 e 42,79289 para as Fácies C e B, respectivamente.

\section{Discussão e Conclusões}

No teste com barra feito por Conyers e Lucius (1996) a anomalia resultante de formato hiperbólico, conforme representada na Figura $11 \mathrm{a}$, com o ápice da hipérbole indicando a posição do alvo no tempo. Esse mesmo padrão hiperbólico, associado a presença da barra, é encontrado neste estudo (Figura 11b), e os valores de TWT utilizados para estimativa de velocidade são os valores onde se encontram os ápices das hipérboles.

a)

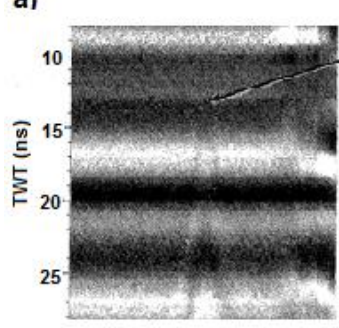

b)

Figure 11 - Anomalias com formato hiperbólico associadas aos alvos (barra) no teste feito por a) Conyers e Lucius (1996) e b) neste estudo.

A antena de $200 \mathrm{MHz}$ foi capaz de detectar os alvos em meio as variações litológicas do afloramento PST. A diminuição no alcance do sinal em determinados trechos do perfil (aquisição com alvo) pode estar relacionada com a geometria pontual do alvo em relação a antena agindo como uma fonte de difração, de modo que o sinal emitido sobre ele colapse com as frentes de ondas defasadas emitidas pela difração. Outro fator que explica a perda de alcance é devido à natureza condutiva do alvo, de modo que, ao sofrer ação de um pulso eletromagnético são geradas correntes elétricas no corpo que resultam em perda de energia térmica como produto final.

A título de comparação foi gerada uma tabela (Tabela 1) com valores de permissividade relativa encontrada em diversas literaturas com abordagens semelhantes e distintas deste estudo.

Tabela 1 - Valores de permissividade elétrica relativa retiradas de distintas literaturas para comparação.

\begin{tabular}{ccc} 
Referências & Arenito $(\varepsilon r)$ & Siltito $(\varepsilon r)$ \\
\hline $\begin{array}{c}\text { Burger, } \\
\text { Sheehan e } \\
\text { Jones (1992) }\end{array}$ & $3-10$ & $5-40$ \\
$\begin{array}{c}\text { Telford, Geldart } \\
\text { e Sheriff (1990) } \\
\text { Save (2004) }\end{array}$ & $4,7-12$ & $7-43$ \\
$\begin{array}{l}\text { Weissling \& } \\
\text { Rubio (2009) }\end{array}$ & $3-5$ & - \\
$\begin{array}{c}\text { Shuqui \& Zhen } \\
\text { (2013) }\end{array}$ & 6,5 & - \\
Este estudo & 6,04957 & $5-30$ \\
\hline
\end{tabular}


Na Tabela 1 fica possível verificar que os valores obtidos neste estudo são de ordens compatíveis com os disponíveis em literatura. Por tanto, o teste com barra metálica adotado para estimativa de velocidade forneceu resultados consistentes. Os parâmetros petrofísicos de velocidade de onda eletromagnética e de permissividade elétrica dos estratos com ocorrência de carvão fornecerão valores de calibração precisos para futuras campanhas de GPR em localidades que possuam características litológicas semelhantes, ainda agregando potencial para aplicação do método de GPR como apoio a exploração de carvão na região de Candiota.

\section{Referências}

ANNAN, A. P. 2005. Near-Surface Geophysics Part 1: Concepts and Fundamentals. 1. ed., cap 11, p. 357-438.

BURGER, R. H; SHEEHAN, F. A; JONES, H. C. 2006. Introduction to Applied Geophysics: Exploring the Shallow Subsurface. Norton \& Company, Inc., New York.

CONYERS, L. B., LUCIUS, J. E. 1996. Velocity Analysis in Archaeological Ground-Penetrating Radar Studies. Archaelogical Prospection. 3, 25-38.

CPRM - Serviço Geológico do Brasil. 2017. Disponível em <http://geobank.cprm.gov.br>. Acesso em 05 de Abril de 2017.

DANIELS, D. 2004. Ground penetrating radar, 2nd ed. Lodon: The Institution of Electrical Engineers,

GOOGLE EARTH. Software disponível em <https://www.google.com.br/intl/pt-BR/earth/>. 2017. Acesso em 05 de Abril de 2017.

HATHERLY, Peter. 2013. Overview on the application of geophysics in coal mining. Internation Jornal of Coal Geology. 114, 74-84.

HOLZ, M. et al. 2006. Hierarchy of tectonic controlo $n$ stratigraphic signatures: Base-level changes during the Early Permian in the Paraná Basin, southernmost Brazil. Journal of South American Earth Scienses. 22, 185-204.

JAMES, Noel P. DALRYMPLE, Robert W. 2010. Facies Models 4. Volume 4. Canada: Geological Association of Canada.

JOL, Harry M. 2009. Ground Penetrating Radar: Theory and Applications. 1 ${ }^{a}$ Edição. Kidlington: Oxford.

KAl et al. 2012. Application of Ground Penetrating Radar (GPR) on the Controlling of the Coalfield Fire. International Journal of Advancements in Computing Technology. 4, 239-246.

KALKREUTH, W. et al. 2006. Petrology and chemistry of Permian coals from the Paraná Basin: 1. Santa Terezina,
Leão-Butiá and Candiota Coalfields, Rio Grande do Sul, Brazil. International Journal of Coal Geology. 68, 79-116.

MOLINDA, G. M. et al. 1996. Using Ground Penetrating Radar for Roof Hazard Detection in Underground Mines. Report of Investigations:9625. United States Department of Energy: Pittsburgh Research Center.

NEAL, Adrian. 2004. Ground-penetrating radar and its use in sedimentology: principles, problems and progress. Earth-Science Reviews, Wolverhampton, 66, 261-330.

RAMGRAB, Gilberto, WILDNER, Wilson. 1999. Carta Geológica Folha Pedro Osório (SH. 22- Y-C), RS. Projeto de Mapeamento Geológico/Metalogenético Sistemático (CPRM). Universidade de São Paulo: Departamento de Engenharia de Minas e Petróleo. (2011)

RAMGRAB, Gilberto, WILDNER, Wilson. 1999. Geologia da Folha Pedro Osório (SH. 22- Y-C), RS. Projeto de Mapeamento Geológico/Metalogenético Sistemático (CPRM). Universidade de São Paulo: Departamento de Engenharia de Minas e Petróleo. (2011)

REFLEXW, Software. 2014. Sandmeier Geophysical Research.

SAVE, N. 2004. Ground Penetrating Radar Technique to Locate coal mining related features. Texas: Texas A\&M University,

SECCATORE, J. MARIN, T. TOMI D. G. 2011. Aplicabilidade do Método de Lavra "Longwall top coal caving" nas Jazidas de carvão na Região Sul. Net. São Paulo, Universidade de São Paulo. jan. Disponível em http://www.researchgate.net/publication/277669450

STRANGE, Andrew et al. 2005. Near-Surface Interface Detection for Coal Mining Applications Using Bispectral Features and GPR. Subsurface Sensing Technologies and Applications, 6 (2), 125-149.

SHUQUI, W. ZHEN, W. 2013. Ground Penetrating Radar Signal Processing Algorithm in Advance Detection of Coal Seam. Information Technology Journal. 12 (19), 52585263.

TELFORD, W. M.; GELDART, L. P.; SHERIFF, R. E. 1990. Applied Geophysics. 2a Edição. Cambridge University Press.

THOMAS, Larry. 2013. Coal Geology. 2ª Edição. United Kingdom: John Wiley \& Sons, Ltd.

WEISSLING, B. RUBIO, G. 2009. Evaluating GPR for Geotechnical and Hazards Assessment of Deep-Mine Geology. FastTimes, 14 (1), 26-31. 
a)

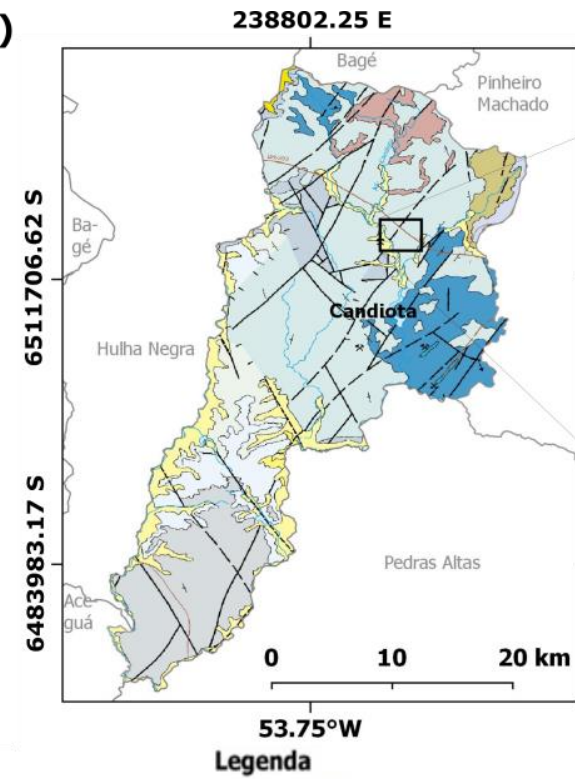

b)

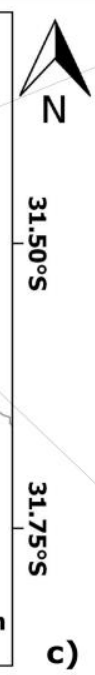

c)

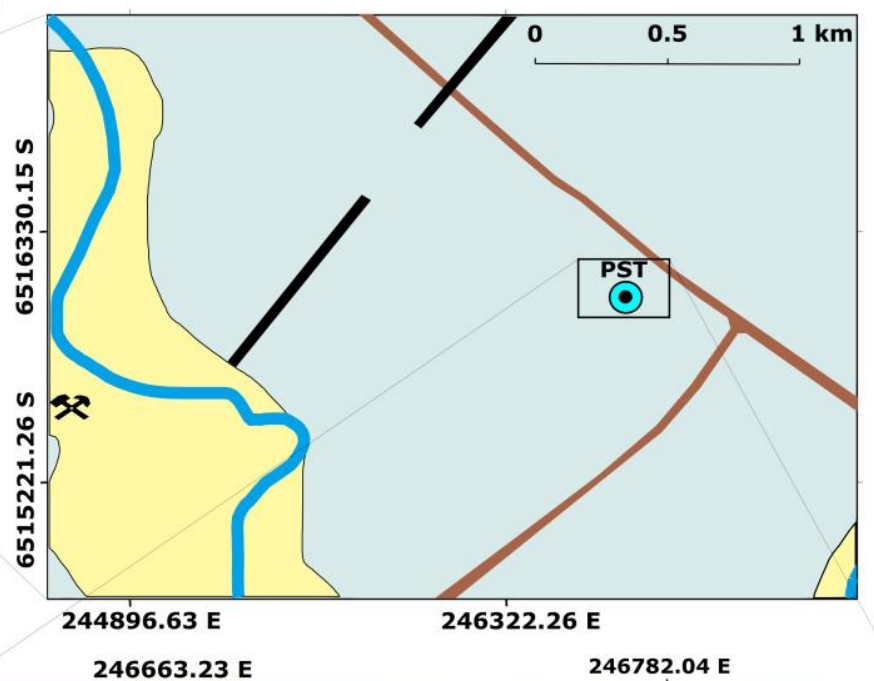

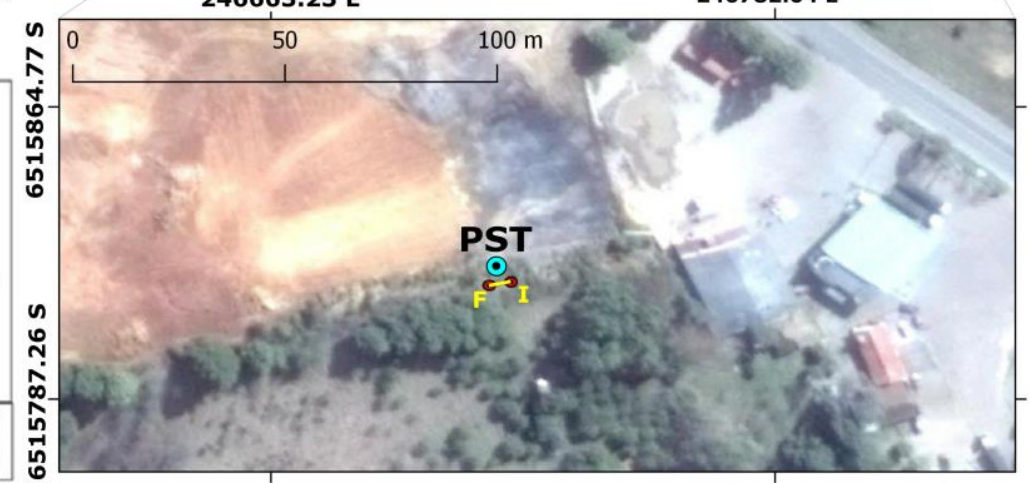
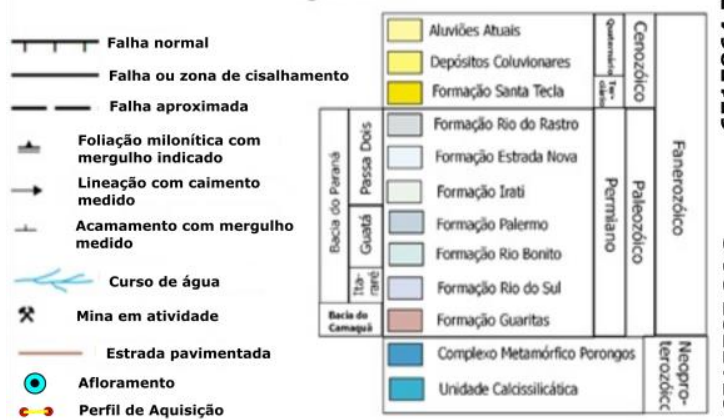

Figura 2 - Mapa a) geológico do munícipio de Candiota, b) do local de estudo destacando em c) imagem de satélite o afloramento PST e perfil de aquisição de dados (datum: SIRGAS2000), adaptado da carta geológica Folha Pedro Osório SH.22-Y-C 1:250000 (CPRM, 1999) e Google Earth Pro (2017). 